\title{
Social Media Implementation: Directive To Action
}

Andrew Mangle, Morgan State University, USA

Jigish Zaveri, Morgan State University, USA

\begin{abstract}
This case is based on the authors' external review of the development, design, and implementation of a social media project at the Maryland Automobile Insurance Fund (MAIF). Both public and private sector companies are seeking social media as an additional approach to engaging customers. The use of social media, in this case, will provide students with an opportunity to examine and analyze the issues and challenges encountered by MAIF and similar organizations' foray into social media. The case immerses the reader in the development of a social media project, requiring project analysis, evaluating multiple solutions, and assessing the challenges posed by alternative approaches. Additionally, the reader will have to propose a planning strategy that will build support consensus among the varying stakeholders while aligning with MAIF's mission. The case allows a professor to discuss possible solutions and encourage students to develop their own individual approaches. Students will be able to outline the objectives of the project and then provide a supporting strategy.
\end{abstract}

Keywords: Social Media; Project Planning; Project Implementation; Stakeholder Analysis

\section{OVERVIEW OF THE MARYLAND AUTOMOBILE FUND'S (MAIF) SOCIAL MEDIA PROJECT}

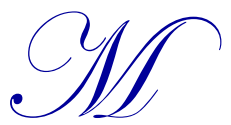

rs. Ann Dormer, Public Information Officer of the Maryland Automobile Insurance Fund (MAIF), was directed to create a social media presence by CEO Mr. Kirk Knight. MAIF is unique among automobile insurance companies because the state government created it as a support agency to sell insurance to those individuals whose driving history precluded them from being insured in the private market. As a secondary responsibility, MAIF manages claims involving uninsured motorists. Also, as a government agency, MAIF is charged with the mission of contributing to the safety of Maryland's driving public. MAIF has not previously participated in social media.

Mrs. Dormer must determine how to use social media to accomplish the mission of MAIF. In responding to the challenge, Mrs. Dormer had to operate within the government's restrictions on MAIF, identify potential project participants, engage key stakeholders, garner project support, and generate a proposal for implementation. The most significant restrictions were that MAIF was not allowed to compete with the private insurance providers and could not directly solicit customers.

In Mrs. Dormer's efforts to identify key stakeholders and to better understand their positions on Mr. Knight's directive, she interviewed several employees and end-users. Mr. Mark Allen, Network and Support Manager, was initially against MAIF's engagement of social media. The Executive Board, in the past, had resisted an internet presence other than a static homepage. However, Mr. David Fritz of MAIF's Human Relations Office was an early supporter of MAIF creating a social media system. Mr. Frank Drake, despite being an intern and not in a regular prominent or influential position, became a key individual advocating for a MAIF social media strategy extending beyond restricted postings. The analysis of the employee feedback was an important consideration as Mrs. Dormer moved forward with the project. 


\section{LAUNCHING MAIF'S SOCIAL MEDIA PROJECT}

"Make it happen!" were the last words Mrs. Ann Dormer heard as her manager, Mr. Kirk Knight, walked out of her office. Mrs. Dormer was just presented with a high priority project with little direction on how to meet his high expectations. In the past, Mrs. Dormer had accomplished multiple projects with tight deadlines, including team-focused collaborations, but she was not prepared for the challenges presented in implementing a complete social media project. This was a major test of her experience and flexibility to develop innovative solutions. Mr. Knight wondered how the Maryland Automobile Insurance Fund (MAIF) could interact with the public through Facebook and asked "Why doesn't MAIF have a Facebook page?" "We need to utilize social media as soon as possible. We're missing out on a great opportunity. Start a MAIF page by the end of the month." Without fully understanding how MAIF would be able to create a social media presence or why it would be beneficial, Mrs. Dormer was determined to meet the expectations and enthusiastically replied, "You will be MAIF's first fan!"

\section{MAIF OVERVIEW}

The Maryland Automobile Insurance Fund (MAIF) was created in 1972 by the Maryland State Legislature and is unique among automobile insurance companies. MAIF is at a disadvantage due to government restrictions on direct marketing, limited resources, and minimal service area. MAIF is required to actively encourage drivers to return to the private insurance market after three years of accident-free driving; the organization must make annual contact with policyholders to remind them to consider alternative insurance providers and persuade them to seek outside insurance coverage. MAIF has the overall goal of encouraging safe driving and promoting public awareness of traffic dangers while not competing with the private insurance market.

\section{Kirk Knight - CEO - Project Sponsor}

Mr. Kirk Knight, MAIF's CEO, had been following the latest industry news and trends about small and medium-sized businesses using social media to connect and build relationships with their customers. Policyholder awareness is a concern for MAIF, the State of Maryland, and the general public. MAIF has a state mandated obligation to inform the public, as well as individual drivers, about the potential risks of driving without or with insufficient insurance. Furthermore, Maryland drivers are to be aware of the role MAIF plays in resolving claims in accidents involving an uninsured, under-insured, or unknown driver. Mr. Knight envisioned Mrs. Dormer developing and implementing a social media strategy that would facilitate in attaining MAIF's goals.

\section{Ann Dormer - Communication Specialist - Project Manager}

Mrs. Dormer has led MAIF's outreach efforts and developed internal and external opportunities, such as employee volunteer events, fundraising campaigns, and management of correspondence with other state agencies. She believed that increased public contact, using social media, will enable MAIF to provide better protection to drivers and improve the overall safety of the community. Even though Mrs. Dormer was familiar with social media through personal involvement, the development of a plan and strategy for an enterprise social media project was challenging and complex.

Mrs. Dormer relied upon the contributions of MAIF team members to support her development of the social media project. Mrs. Dormer chose to initiate the project by meeting with key decision-makers. During her interactions, she listened to the insights of colleagues regarding their beliefs about the potential impact of MAIF's participation in social media. Without prior systems development experience, a key to her success was following an established planning process. A detailed understanding of the key stakeholders' initial positions on the proposed project enabled Mrs. Dormer to manage and reduce resistance.

\section{Mark Allen - Network and Support Manager}

Mr. Mark Allen was in charge of MAIF's internal and external networks, as well as overseeing the IT support group. As part of the IT senior management team, he has an active role in all technology-based projects. The Network and Support team reviews and approves all IT projects before implementation. When approached by 
Mrs. Dormer about the project, Mr. Allen was hesitant to encourage the development of projects that would require support from his unit. Mr. Allen was also opposed to participating in social media due to MAIF's position as a state agency with limited resources. He believed that without significant investment of time and personnel resources, a MAIF Facebook page or another social media platform would never generate enough benefits to justify the efforts. Mr. Allen recommended an alternative approach of creating a single Facebook fan page which would redirect all correspondence and communication through MAIF's homepage. Mrs. Dormer listened to the suggestion and proposed discussing other possible alternatives at the next Executive Board meeting.

\section{MAIF's Executive Board}

The Executive Board - the governing body responsible for approving policies and procedures - is in charge of individually reviewing, revising, and approving MAIF's technology projects. When MAIF had set up their original homepage, the Executive Board had expressed concern over the security, potential release of misinformation, and the overall management of the webpage. The Executive Board requested that the website be protected from malicious users as well as separated from the operations of the organization. Another concern was the potential for sharing outdated or incorrect information that could hurt the MAIF brand and endanger Maryland citizens. The Executive Board alternately proposed static profile pages on Facebook, Twitter, and YouTube. On each MAIF page, basic information, including hours of operation, directions, and contact information, would be posted. Customers, agents, employees, and friends of MAIF could friend, follow, and 'like' the pages, but no dynamic information would be posted.

\section{David Fritz - Social Media Contributor}

After the Executive Board meeting, the HR director recommended that Mrs. Dormer talk to one of her staff members, Mr. David Fritz, who had - unsuccessfully - requested approval from the Board for an interactive Facebook page to represent MAIF's HR office. Mr. David Fritz was an avid participant in social media and maintained several different social media accounts that corresponded with his external activities and interests. Mr. Fritz had advised individuals about several different social media platforms for personal use based upon his personal experiences independent of MAIF. When Mrs. Dormer approached Mr. Fritz for his input on starting a MAIF page, Mr. Fritz exclaimed, "Social media would be great for MAIF! When can we set up the accounts?" He was quick to support the notion of MAIF initiating a social media project. "We could upload photos of events, videos, and helpful links." When Mrs. Dormer asked Mr. Fritz how he would handle the questions raised by the Executive Board, he asserted that someone could be designated as the content monitor as part of his job duties. The selected employee could be notified of any posted content. The meeting between Mr. Fritz and Mrs. Dormer ended with a recommendation for her to speak with Mr. Frank Drake, an intern.

\section{Frank Drake - Social Media Entrepreneur}

Frank Drake was a junior, majoring in Business Administration at a local college. Mr. Drake's passion was electronic music, specifically sampling and sharing tracks using social media. Mrs. Dormer asked Mr. Drake about his approach to designing a successful social media system. Mr. Drake supported an open approach where anyone could post and share information, saying, "Everyone should be able to freely interact using social media." When asked about the risks of negative feedback, including inappropriate posts and abusive behavior, he replied, "the community polices itself and, in the worst case, any post could be deleted." Mr. Drake managed several social media accounts and encouraged Mrs. Dormer to consider creating multiple accounts for the numerous departments in MAIF. Mr. Drake closed the conversation in a reassuring manner, stating, "What's the worst that could happen with social media? - someone doesn't 'like' the MAIF page?"

\section{CONCLUSION - NEXT STEPS}

Mrs. Dormer was reluctant to start a social media engagement project knowing the complexities involved with managing this type of information system. When Mr. Knight had first presented her with the idea, she was flooded with a wide range of thoughts, perspectives, and strategies. These ideas became more controversial and complex as she solicited and obtained the views of the different stakeholders. Even though MAIF has a vast array of 
resources, the planning, developing, and implementing of the system needed to be coordinated and executed effectively. As Mrs. Dormer pondered potential approaches and solutions, the project deadline was looming. Mrs. Dormer must leverage her knowledge of MAIF and social media, her available technology resources, and the stakeholders' concerns in order to develop a successful social media system for MAIF. How does the Public Information Officer accomplish the social media directive in one month?

\section{TEACHING NOTES}

Supplemental teaching notes are available from the corresponding author. The teaching notes include recommendations on required knowledge, prompts and questions to encourage class participation and discussion, information on decisions made by MAIF staff, and proposed time frames and assignments for two undergraduate classes. Additionally, an epilogue, including MAIF's selected social media solution, is also available.

\section{AUTHOR INFORMATION}

Andrew Mangle is an Assistant Professor in the School of Applied and Information Technology at the Community College of Baltimore County and a Ph.D. candidate (ABD) in the Department of Information Science and Systems, Earl Graves School of Business and Management at Morgan State University. He has presented his research at numerous conferences including the International Academy of Business and Economics and the Hawaiian International Conference on Business. E-mail: amangle@gmail.com (Corresponding author)

Dr. Jigish Zaveri is an Associate Professor in the Department of Information Science and Systems, Earl Graves School of Business and Management at Morgan State University. He received the Ph.D. (1992, Management Information Systems) and M.S. (1988, Chemical Engineering) degrees from University of Kentucky. Dr. Zaveri's research interests encompass Knowledge Management, Research Methods, Decision Support Systems, Organizational Learning, Artificial Intelligence, and others. He has numerous research publications that have appeared in Decision Science, Journal of Information Systems Education, IEEE Transactions on Systems, Man, and Cybernetics, Journal of Information Systems Education, Decision Support Systems, Information Systems Education Journal, Journal of Digital Business, and others. He also has several book chapters in Handbook of Decision on Decision Support System (Springer), Encyclopedia of Healthcare Information Systems (IDEA group), Manufacturing Decision Support Systems (Chapman-Hall), and others. He also has more than 50 research presentations and articles presented at major national and international conferences. Additionally, Dr. Zaveri has worked on numerous funded projects for several agencies including the Department of Homeland Security, the National Transportation Center, the National Security Agency, Applied Physics Laboratory at Johns Hopkins University, Maryland Department of Transportation, and others. E-mail: jzaveri00@yahoo.com

\section{REFERENCES}

1. Ernoff, J., \& Li, C. (2008) "Harnessing the power of the oh-so-social web," MIT Sloan Management Review, Vol. 49, No. 3, pp. 36-42.

2. Ellison, N. (2007) "Social Network Sites: Definition, History, and Scholarship," Journal of Computer Mediated Communication, Vol. 13, No. 11, pp. 210-230.

3. Kaplan, A., \& Haenlein, M. (2010) "Users of the World, unite! The Challenges and Opportunities of Social Media," Business Horizons, Vol. 53, No. 1, pp. 59-68.

4. Li, C., \& Bernoff, J. (2008) Groundswell: Winning in a World Transformed by Social Technologies, Harvard Business School Publishing, Boston, MA.

5. Mangold, W., \& Faulds, D. (2009) "Social Media: The New Hybrid Element of the Promotion Mix," Business Horizons, Vol. 52, No. 4, pp. 357-365.

6. Shuen, A. (2008) Web 2.0: Strategy Guide Business Thinking and Strategies Behind Successful Web 2.0 Implementations, O'Reilly Media, Sebastopol, CA

7. Wilson, H., Guinan, P., Parise, S., \& Weinberg, B. (2011) “What's Your Social Media Strategy?" Harvard Business Review, Vol. 7, No. 8, pp. 23-25.

8. Wollan, R., Smith, N., \& Zhou, C. (2011) The Social Media Management Handbook: Everything You Need To Know To Get Social Media Working In Your Business, Wiley, Hoboken, NJ. 